\title{
A prebiotic effect of Ecklonia cava on the growth and mortality of olive flounder infected with pathogenic bacteria
}

WonWoo Lee ${ }^{\mathrm{a}}$, Ginnae Ahn ${ }^{\mathrm{b}}$, Jae Young $\mathrm{Oh}^{\mathrm{a}}$, Seung Min Kim${ }^{\mathrm{a}}$, Nalae Kang ${ }^{\mathrm{a}}$, Eun-A Kim ${ }^{\mathrm{a}}$, Kil-Nam Kim ${ }^{\mathrm{c}}$, You-Jin Jeon ${ }^{\mathrm{a}, *}$

${ }^{a}$ Department of Marine Life Science, Jeju National University, Jeju 690-756, Republic of Korea

${ }^{b}$ Department of Marine Bio-food Science, College of Fisheries and Ocean Sciences, Chonnam National University, 500-749, Republic of Korea

${ }^{c}$ Marine Bio Research Team, Korea Basic Science Institute (KBSI), 690-140, Korea

*Corresponding author: Tel: +82-64-754-3475; Fax: +82-64-756-3493; E-mail: youjinj@jejunu.ac.kr 


\begin{abstract}
Olive flounder (Paralichthys olivaceus), also known as the Japanese flounder in Japan, is one of the most important commercial marine finfish species cultured in Korea and Japan. The purpose of this study was to evaluate how a species of brown algae (Ecklonia cava) affects the growth rate of olive flounder and its immune response to pathogenic bacteria. First, the experimental fish were divided into four groups: the control group was fed the diet containing only $1.0 \%$ Lactobacillus plantarum (L. plantarum), group I was fed $1.0 \% \mathrm{~L}$. plantarum and $1.0 \%$ Ecklonia cava (EC), group II was fed $1.0 \%$ L. plantarum and $0.1 \%$ ethanol extract of EC (EE), and group III was fed 1.0\% L. plantarum and 0.5\% EE.The diets fed to the fish twice a day for 16 weeks. The results indicated that supplementation with $1.0 \%$ EC and $0.1 \%$ EE improved the growth and body weight of olive flounder, and decreased its mortality. This diet, however, did not significantly affect the biochemical profiles of the experimental flounder. The supplementation of $1.0 \% \mathrm{EC}$ also enhanced the innate immune response of the fish, as evidenced by the high respiratory burst, and increased serum lysozyme and myeloperoxidase activity. The addition of $1.0 \%$ EC and either $0.1 \%$ or $0.5 \%$ EE also decreased the accumulative mortality of olive flounder infected by pathogenic bacteria (Edwardsiella tarda, Streptococcus iniae, and Vibrio harveyi). Overall, these results suggest that $E$. cava can act as a prebiotic by improving the innate immune response in fish infected with pathogenic bacteria as increased the growth of the probiotic.
\end{abstract}

Keywords

Prebiotic; Ecklonia cava; Olive flounder; Lactobacillus plantarum; Innate immune response

\title{
1. Introduction
}

During the last 15 years, cultured fish production has more than doubled, and marine 
aquaculture industries in South Korea now produce a number of fish species $[1,2,3,4]$. In particular, the olive flounder is one of the most important commercial marine aquaculture species in Korea, and improvements to culturing techniques have increased its production [5]. Recently, however, outbreaks of infectious disease caused by viruses, bacteria, and parasites in aquaculture facilities have inflicted severe damage to fish production in Southeast Asia, which in turn has become a major economic problem [2]. Bacteria have been identified as being responsible for the majority of economic losses [6]. In cultured olive flounder, the most common pathogenic bacteria are Edwardsiella tarda, Streptococcus sp. and Vibrio sp. [7]. Edwardsiella tarda affects both freshwater and marine fish, causing septicemia, skin lesions, and diseases of the muscles and internal organs, including the liver, kidney, and spleen [8]. Streptococcus sp. infection in fish is considered as a re-emerging disease affecting a variety of wild and cultured fish. These infections are actually a complex of diseases caused by different genera and species, and affect the central nervous system, causing suppurative exophthalmia and meningoencephalitis [6]. Pathogenic Vibrio sp., the etiological agent of classical vibriosis, is widely distributed, and it causes hemorrhagic septicemia in a variety of warm- and cold-water fish species of economic importance [6]. Researchers have studied the treatment of bacterial diseases using antibiotics and chemotherapeutics $[9,10,11,12]$. However, antibiotics use in aquaculture may be detrimental to the environment and human health, and it causes the development and transfer of resistance to other aquatic bacteria [13], fish pathogens, and human pathogens, and the accumulation of residual antibiotics in aquaculture products $[13,14,15,16,17]$.

Probiotics, especially lactic acid bacteria (LAB), have been widely employed to protect fish against infectious diseases [18], including edwardsiellosis, furunculosis, and vibriosis $[19,20,21]$. In addition, LAB probiotics are safe to use in fish that will be consumed and they also protect against harmful pathogens by inhibiting the growth of Aeromonas salmonicida, 
Vibrio anguillarum, and Flavobacterium psychrophilum, as shown in rainbow trout [19,21]. For these reasons, the use of probiotics as a strategy to control fish pathogens is increasing $[22,23,24,25]$. Interestingly, prebiotics can enhance the growth of probiotics and induce their production of bioactive secondary metabolites. Therefore, probiotics and prebiotics can be useful in the study of how such components can limit bacterial disease in olive flounder.

Recently, the biological roles of Ecklonia cava (E. cava), a brown seaweed contains polyphenol and polysaccharide compounds as major components have been reported [26, 27]. Especially, LBA-fermented E. cava increased the protein contents in comparison with the non-fermented $E$. cava [26,28]. However, until now, there is no report about effect of $E$. cava as a prebiotic in cultured olive flounder.

Therefore, the present study investigated the use of E. cava as a prebiotic in cultured olive flounder and evaluated its effect on the immunological response of fish infected with pathogenic bacteria.

\section{Materials and Methods}

\subsection{Preparation of experimental diets containing $E$. cava and L. plantarum}

E. cava was collected along the coast of Jeju Island in South Korea during the period from March to May 2011 and identified by Dr. Lee (Jeju National University, South Korea, voucher specimen: Jeju-C-47). It was washed with fresh water, freeze-dried, and then pulverized into powder with a grinder. A previous study indicated the effect of E. cava polysaccharide on the growth of probiotics was similar to that of the original E. cava powder [26]. Therefore, the original E. cava powder (EC) was used in this study. To prepare the ethanol extract of E. cava (EE), which contains rich polyphenols with antibacterial effects, the powder $(20 \mathrm{~kg})$ was homogenized in $2 \mathrm{~L}$ of $100 \%$ ethanol. After $24 \mathrm{~h}$, the EE was evaporated, freeze-dried, and then kept at $-20^{\circ} \mathrm{C}$ for later experiments. The experimental diets 
were prepared by adding $0.1 \% \mathrm{EE}, 0.5 \% \mathrm{EE}$, or $1.0 \% \mathrm{EC}$ to the soft extruded pellets (Daebong susan, Jeju, Korea, Table 1). In addition, $1.0 \%$ of $L$. plantarum was added to all of the diets as a probiotic. The experimental diets were fed to all fish twice a day for 16 weeks.

\subsection{Preparation of cultured olive flounder fish for the field trial}

Olive flounder (mean body weights 300 to $350 \mathrm{~g}$ ) were purchased from a private hatchery (Geumdeung, Jeju Island, South Korea) and acclimated for one week. The field trial was performed in Manhae susan (Pyoseon-ri, Pyoeonmyeon, Jejudo, South Korea) for 16 weeks (February 2013 to May 2013). Cylindrical polypropylene (PP) tanks (8 $\mathrm{m}$ in diameter and $1.5 \mathrm{~m}$ in height) were used to house the fish. Each tank was stocked with 1,800 olive flounders, and the water was changed 10-15 times a day before samples were taken during the feeding trial. Seawater temperature $\left(16-18^{\circ} \mathrm{C}\right)$, dissolved $\mathrm{O}$ content $(8.23-9.37 \mathrm{mg} / \mathrm{L})$, salinity (27.68-31.36 ppt), and $\mathrm{pH}(7.5-8.7)$ were maintained in their respective ranges during the experimental feeding period. During the 16-week trial, the fish were fed their respective diets (as described in section 2.1.1.) twice a day at 06:00 $\mathrm{h}$ and 17:00 $\mathrm{h}$.

The experimental fish were divided into four groups: the control group was fed the diet containing only $1.0 \%$ L. plantarum, group I was fed $1.0 \%$ L. plantarum and $1.0 \%$ EC, group II was fed $1.0 \%$ L. plantarum and $0.1 \%$ EE, and group III was fed $1.0 \%$ L. plantarum and $0.5 \%$ EE.

\subsection{Measurement of body weight and mortality in olive flounder}

During the experimental period, the body weights and mortality of the olive flounder were recorded every 4 weeks for 16 weeks.

\subsection{Analysis of biological indices in the serum of olive flounder}

To investigate the effects of EC and EE on the biochemical blood profiles of the experimental olive flounder, blood samples were collected from the fish by a heparin-coated needle at 0 and 16 weeks of the experimental period. Individual fish were sampled only once 
to prevent multiple bleeds and stress from affecting the assays. The blood was allowed to clot or $30 \mathrm{~min}$ and then kept at $4{ }^{\circ} \mathrm{C}$ for $3 \mathrm{hr}$. Then, the clotted samples were centrifuged at 3000 rpm for $10 \mathrm{~min}$ at $4^{\circ} \mathrm{C}$ and the serum was collected and used to analyze total protein (TP), triglycerides (TRIG), aspartate aminotransferase (AST), alanine aminotransferase (ALT), glucose (GLU), phosphorus (PHOS), cholesterol (CHOL), and hematocrit (HT) with biochemical analysis kits (STANBIO, TX, USA) and an automatic analyzer (Boehringer Mannheim, Mannheim, Germany).

\subsection{Effects of EC and EE on the innate immunity of olive flounder}

Normally, lysozyme can either act as an innate opsonin, or have lytic activity. To evaluate the effects of EC and $\mathrm{EE}$ on the innate immunity of olive flounder, we investigated respiratory burst activity by measuring neutrophils, lysozyme function, and myeloperoxidase (MPO) activity with slight modifications of previously suggested methods [1,29]. This testing was done using previously collected serum samples at 0 and 16 weeks into the experimental period.

\subsection{Polymerase chain reaction analysis}

To determine whether the olive flounder was successfully infected with the three administered bacteria (E. tarda, S. iniae and V. harveyi), samples of kidney and liver tissue from fish injected with the bacteria were subjected to polymerase chain reaction (PCR) analysis. The cDNA purified from the kidney and liver samples was used with the primers of the three bacteria (Bioneer, Daejeon, South Korea), shown in Table 2. Then PCR analysis was performed for 40 cycles with a 5 min denaturing step at $94^{\circ} \mathrm{C}$, a 1 min annealing step at 55 to $60^{\circ} \mathrm{C}$, and a 20 min extension phase at $72^{\circ} \mathrm{C}$ using the TaKaRa PCR machine (Takara Bio, Shiga, Japan). All PCR products were run on a $1.5 \%$ agarose gel, and visualized by UV transillumination.

\subsection{Challenge test with bacterial infection}


Samples of the pathogenic bacteria used in the study (E. tarda, S. iniae, and V. harveyi) were obtained from the KCTC (Korean Collection for Type Culture, Daejeon, Korea). First, E. tarda and $S$. iniae were incubated in BHIA broth and $V$. harveyi in TSA broth at $25^{\circ} \mathrm{C}$ until they were needed. Fish were divided into four groups (30 fish per group). Each group was given dietary supplements with $1.0 \%$ EC, $0.1 \%$ EE, or $0.5 \%$ EE. Another group of 30 fish was a control (uninfected) group that was fed a basal diet. Before the experimental feeding was initiated, all fish were respectively injected intraperitoneally with $100 \mu \mathrm{l}$ PBS containing

E. tarda, S. iniae, and $V$. harveyi at $3 \times 10^{5}$ ciliates $\mathrm{mL}^{-1}$. One day after the bacterial challenge, six fish were randomly collected from each tank and anesthetized with MS-222 $\left(\mathrm{NaHCO}_{3}\right.$ and tricaine methanesulfonate; Sigma Aldrich Inc., St. Louis, $\left.\mathrm{MO}\right)$ in dechlorinated water for $2 \mathrm{~min}$. The cumulative mortality was calculated with the formula described by [30] every day for 2 weeks.

\section{Results}

\subsection{EC enhanced the growth of olive flounder by increasing body weight}

The body weights $(\mathrm{g})$ of fish were recorded every 4 weeks for 16 weeks. The growth of olive flounder fed the experimental diet containing $1.0 \%$ L. plantarum for 16 weeks is shown in Fig. 1A and 1B. During this time, the body weights of all fish fed the $1.0 \%$ EC diets were higher than those of fish fed the other diets (Fig. 1A). However, both the $0.1 \%$ EE and $0.5 \%$ EE diets showed similar or lower body weights than the control group for all experimental periods (Fig. 1A). Also, as shown in Fig. 1B, we found that the final body weights of fish increased by $108 \%$ when they were fed the $1.0 \%$ EC diet for 16 weeks; in contrast, neither EE supplement had this effect. These results demonstrate that the supplementation of EC effectively improved the growth of olive flounder.

\subsection{Both $1.0 \%$ EC and $0.1 \%$ EE decreased the mortality of olive flounder}


To access the effects of $1.0 \% \mathrm{EC}, 0.1 \% \mathrm{EE}$, and $0.5 \% \mathrm{EE}$ on the mortality of olive flounder, the number of deceased fish was counted every 4 weeks for 16 weeks. The number of dead fish in the control group increased markedly (up to nearly $316 \%$ at 4 weeks), and then gradually decreased over the following 12 weeks (Fig. 1C). However, the supplementation of $1.0 \% \mathrm{EC}$ and $0.1 \% \mathrm{EE}$ resulted in lower mortality than that of the control group throughout the experimental period. Moreover, the accumulated mortality of the fish fed the control diet was markedly increased (a total of approximately 636 fish over 16 weeks), whereas the mortality decreased by $18 \%$ and $13 \%$ in fish supplemented with $1.0 \% \mathrm{EC}$ and $0.1 \% \mathrm{EE}$, respectively (Fig. 1D and 1E).

\subsection{The supplementation of $1.0 \%$ EC, $0.1 \%$ EE, and $0.5 \%$ EE did not significantly affect the biochemical profiles of olive flounder}

To assess the effects of $1.0 \% \mathrm{EC}, 0.1 \% \mathrm{EE}$, and $0.5 \% \mathrm{EE}$ on the biochemical profiles of olive flounder, serum was collected from the fish at 0 and 16 weeks and TP, TRIG, AST, ALT, GLU, PHOS, CHOL, and HT values were measured. None of these levels significantly changed over the course of the experimental period in any of the groups (Table 2).

\subsection{The supplementation of $1.0 \%$ EC improved the growth of olive flounder by enhancing innate immunity}

We identified the effects of $1.0 \% \mathrm{EC}, 0.1 \% \mathrm{EE}$, and $0.5 \% \mathrm{EE}$ on the innate immunity of olive flounder by measuring respiratory burst activity, lysozyme activity, MPO activity, and growth rates. As shown in Fig. 2A, supplementation with $1.0 \% \mathrm{EC}, 0.1 \% \mathrm{EE}$, and $0.5 \% \mathrm{EE}$ considerably increased superoxide anion production compared to the control group. In particular, the supplementation of $1.0 \%$ EC led to the highest respiratory burst activity with enhanced superoxide formation. Figure 2B shows that lysozyme activity was significantly enhanced in fish fed the $1.0 \% \mathrm{EC}, 0.1 \% \mathrm{EE}$, and $0.5 \% \mathrm{EE}$ diets at 16 weeks. In particular, fish fed the $1.0 \%$ EC diet had the highest lysozyme activity compared to the others. 
Furthermore, MPO activity was significantly enhanced in fish fed the $1.0 \% \mathrm{EC}$ and $0.5 \% \mathrm{EE}$ diets at 16 weeks, whereas there was no significant change in the fish supplemented with $0.1 \%$ EE (Fig. 2C). The diet with 1.0\% EC resulted in the highest MPO activity out of all the groups. Moreover, Fig. 2D shows how supplementation with $1.0 \%$ EC improved the growth rate of fish, compared to the control group. These results indicate that the supplementation of $1.0 \%$ EC produced the highest growth rate of olive flounder by enhancing their innate immunity.

\subsection{The supplementation of $1.0 \% \mathrm{EC}, 0.1 \% \mathrm{EE}$, or $0.5 \% \mathrm{EE}$ decreased the cumulative mortality of olive flounder infected by pathogenic bacteria}

In the in vivo trial, deaths resulting from E. tarda, S. iniae, and $V$. harveyi in fish fed diets containing $1.0 \% \mathrm{EC}, 0.1 \% \mathrm{EE}$, or $0.5 \% \mathrm{EE}$ were recorded. First, PCR assay was performed to confirm that the bacteria were actually present in the fish after injection. The results showed mRNA expression levels of specific regions of E. tarda, S. iniae, and $V$. harveyi (Supplement Fig. 1), which confirmed bacterial infection in the fish.

As indicated in Fig. 3, the injection of E. tarda, S. iniae, and V. harveyi markedly increased the cumulative mortalities of the control group over 14 days. When E. tarda was injected into the fish, the fish with supplements in their diet all showed decreased mortality, in contrast to the control group in which mortality increased (Fig. 3A). Among the supplements, $1.0 \%$ EC decreased mortality the most in fish injected with E. tarda (Fig. 3A). In addition, flounder infected with $E$. tarda developed heavy viscous liquid in the body cavity, liver congestion, and abnormal growth of the kidney and spleen, all of which are clinical signs seen in naturally infected olive flounder (data not shown). Interestingly, these changes were inhibited by the supplementation of $1.0 \% \mathrm{EC}, 0.1 \% \mathrm{EE}$, and $0.5 \% \mathrm{EE}$.

In the fish injected with $S$. iniae, the $1.0 \% \mathrm{EC}$ and $0.1 \%$ EE supplements also significantly decreased cumulative mortality compared to the control group, whereas $0.5 \%$ 
EE did not affect the number of deaths (Fig. 2B). Moreover, the supplementation of $1.0 \%$ EC and $0.1 \%$ EE improved the clinical manifestations of fish infected with $S$. iniae, including skin ulcers of the scale-covered parts of the body and diffuse petechiation or hemorrhage of internal organs (data not shown).

Similarly, in the fish infected with $V$. harveyi, supplementation of $1.0 \% \mathrm{EC}$ and $0.1 \% \mathrm{EE}$ significantly decreased the cumulative mortality of the infected flounder (Fig. 3C). However, the $0.5 \%$ EE group showed a similar result to that of the control population. As with the other bacteria, $1.0 \% \mathrm{EC}$ and $0.1 \% \mathrm{EE}$ improved the clinical manifestations of $V$. harveyi infection, including generalized septicemia with hemorrhage at the base of the fins, exophthalmia, corneal opacity, and edematous lesions predominantly at the hypodermis (data not shown). These results indicate that the supplementation of $1.0 \% \mathrm{EC}, 0.1 \% \mathrm{EE}$, and $0.5 \% \mathrm{EE}$ decrease the cumulative mortality of olive flounder infected with pathogenic bacteria.

\section{Discussion}

The present study demonstrates that the supplementation of E. cava with $1.0 \% \mathrm{~L}$. plantarum (a probiotic) supported the growth of olive flounder by enhancing its prebiotic activity, resulting in increased body weight and decreased mortality. The supplementation of EC or EE in diets containing L. plantarum also increased the activities of both lysozyme and MPO, which reduced the cumulative mortality of olive flounder infected with pathogenic bacteria. These results show the potential value of E. cava as a beneficial prebiotic. This is similar to our previous work, in which we showed that $E$. cava stimulates the growth of probiotics and produces various useful components with anti-bacterial effects [26].

A number of supplements containing probiotics or beneficial bacteria have been used to control pathogenic bacteria in fish. Indeed, probiotics have been proposed as an alternative method of improving the growth and health of cultured organisms $[31,32,33]$. The ability of 
probiotics to control disease in fish have been documented in grouper [34,35,36], tilapia [21], sea bass $[37,38]$, and white shrimp $[39,40,41]$. Our results showed that the supplementation of $1.0 \%$ EC with L. plantarum improved the growth and decreased the mortality of olive flounder. The supplementation of $0.5 \% \mathrm{EE}$ also decreased the mortality of olive flounder, but did not affect body weight.

We previously demonstrated that the prebiotic effects of $E$. cava enhanced the growth of LBA and its secondary metabolites by inhibiting the growth of pathogenic bacteria in fish [26]. In addition, [42] reported that the increase in growth rates can be attributed to the improvement of the microbial flora balance in the intestines. These results suggest that EC and LBA can act synergistically to improve the growth and reduce mortality in olive flounder. Overall, the results of this field trial suggest the potential benefits of using E. cava in olive flounder aquaculture.

The innate immune system of fish, while primitive, is the first line of defense against pathogenic bacteria in fish in an aquaculture system [2]. The most important components of the innate immune system include macrophages, monocytes, granulocytes, and humoral elements, such as lysozymes and the complement system [43,44]. Cross reported that the regulatory signals generated by probiotics enhance host immunity against pathogens [45]. Recently, prebiotics have also been found to affect innate immunity both in vitro and in vivo $[46,47,48]$. In addition, probiotic bacteria have been shown to induce proinflammatory cytokines, stimulate the activity of natural killer cells, increase mucosal and systemic antibody production, activate phagocytes, and increase lysozyme and complement activity $[2,35,36,49]$. The influx of phagocytes to the infection site is actually an innate defense mechanism of fish against pathogens [39]. During the respiratory burst, phagocytes produce toxic oxygen forms [40], which are proportional to the intensity of a respiratory burst [50]. In fish specifically, phagocytic cells, including monocytes, macrophages, and/or neutrophils can 
generate superoxide anions, all components of respiratory burst activity, to kill pathogens $[39,51,52]$. In addition, phagocytic cells can induce lysozyme to act as an opsonin, with bactericidal activity and activate the complement system and other phagocytes $[53,54,55]$. Phagocytic cells can also induce MPO activity [56,57].

In our study, the supplementation of $1.0 \% \mathrm{EC}$ and $L$. plantarum in the diets of olive flounder markedly enhanced the innate immune system by activating the respiratory burst and lysozyme and MPO activity, compared to the control group. These results were supported by the ability of LAB to enhance the activity of phagocytes, lysozyme, and complement, as also demonstrated in previous reports [36,58]. Furthermore, our research showed the beneficial effect of E. cava on the growth of LBA [26]. It is possible that these enhancements of the innate immune system protect against pathogenic bacterial infection. Interestingly, the supplements of EC and/or EE with L. plantarum reduced mortality in olive flounder for 2 weeks after being exposed to E. tarda, S. iniae and V. harveyi. Our previous report indicated that the secondary metabolites obtained from E.cava treated L. plantarum, including cyclohexasiloxane, dodecamethyl-, 2,4,6-cycloheptatrien-1-one, 3,5-bis-trimethylsilyl- and 9anthracenyltrimethyl-, inhibited the growth of pathogenic bacteria [26]. Moreover, the polysaccharide components of E. cava and its ferments led to immune enhancement in immune cells and gamma ray-irradiated immune cells [27,28]. The previous study supports our results by indicating the potential capacity of E. cava-treated LAB to improve immunological and antibacterial activity in olive flounder infected with pathogenic bacteria [26,58]. Furthermore, diet supplements with seaweed extracts can influence select genera of gut-associated microbiota [59,60]. More specifically, supplements with fucoidan have been shown to stimulate the growth of lactobacilli in the intestine [60,61]. In addition, recent reports showed that novel dietary polysaccharides derived from seaweed species can affect the gut associated microbiota, which includes the stimulation of LAB such as lactobacilli 
$[60,61]$ and prohibitive effects on detrimental bacteria such Enterobacteria [60], including Escherichia coli [62]. In summary, these results suggest that E. cava can enhance the innate immune system, inhibit pathogenic bacteria growth, promote LAB, and produce secondary metabolites from LAB in the gut-related immune system, all of which contribute to lower mortality in fish infected with pathogenic bacteria.

\section{Conclusions}

In conclusion, diets supplemented with E. cava (a prebiotic) and L. plantarum (a probiotic) can enhance the innate immune system and gut-related microbiota of olive flounder, thereby improving the resistance of these fish to pathogenic bacteria. The evaluation of the commercial cost-benefit analysis of these supplements is an area for future study.

\section{Acknowledgment}

This research was financially supported by the Ministry of Trade, Industry and Energy(MOTIE) and Korea Institute for Advancement of Technology(KIAT) through the Research and Development for Regional Industry.

\section{References}

[1] Cha SH (2007) Effects of fermented fish meal from by-products derived in fish farms and chitosan coating moist pellet on culturing fish. MSc thesis, Jeju National University.

[2] Harikrishnan R, Balasundaram C, Heo MS (2010) Effect of probiotics enriched diet on Paralichthys olivaceus infected with lymphocystis disease virus (LCDV), Fish Shellfish Immunol. 29, 868-874. 
[3] Samarakoon KW, Cha SH, Lee JH, Jeon YJ (2013) The growth, innate immunity and protection against $\mathrm{H}_{2} \mathrm{O}_{2}$-induced oxidative damage of a chitosan-coated diet in the olive flounder Paralichthys olivaceus. Fish Aquat. Sci. 16(3), 149-158.

[4] Yoo G, Bai SC (2014) Effects of the dietary microbial phytase supplementation on bioavailability of phosphorus in juvenile olive flounder paralichthys olivaceus fed soybean meal based diets. Fish Aquat. Sci. 17(3), 319-324.

[5] Kang JH, Kim WJ, Lee WJ (2008) Genetic linkage map of olive flounder, paralichthys olivaceus. Int. J. Biol. Sci. 4, 143-149.

[6] Toranzo AE, Magarinos B, Romalde JL (2005) A review of the main bacterial fish disease in mariculture systems. Aquaculture 246, 37-61.

[7] Go GM (2006) Studies on the utilization of fermente cactis fruit (Opuntiaficus-indica) for olive flounder, Paralichthys olivaceus. PhD thesis, Jeju National University.

[8] Plumb JA (1993) Edward septicemia. In: Inglis, V., Roberts, R.J., Bromage, N.K., editors. Bacterial diseases of fish. Oxford: Black-well. 61-73.

[9] Kim KW, Park GJ, Ok IH, Bai SC, Choi YJ, Shin IS (2002) Effects of dietary synthetic amino acid supplementation in Korean Rockfish fry Sebastes schlegeli. Kor. J. Aquaculture. 15, 157-163.

[10] Kwon MG, Lee YH, Park SU, Kim BS, Park SI (2002) The effects of charcoalin diet on the immune responses of flounder, Paralichthys olivaceus. Kor. J. Fish Pathol. 15, 17-24.

[11] Immanuel G, Vincybai VC, Sivaram V, Palavessam A, Marian MP (2004) Effect of butanolic extracts from terrestial herbs and seaweed on the survival, growth and pathogen (Vibrio parahaemolyticus) load on shrimp Penaeus indicus juveniles. Aquacultur 236, 5365.

[12] Sivaram V, Babu MM, Immanuel G, Murugadass S, Citarasu T, Marian MP (2004) Growth and immune response of juvenile greasy groupers (Epinephelus tauvina) fed with 
berbal antibacterial activite principle supplemented diets against Vibrio harveyi infections. Aquaculture 237, 9-20.

[13] Petersen A, Andersen JS, Kaewmak T, Somsiri T, Dalsgaard A (2002) Impact of integrated fish farming on antimicrobial resistance in a pond environment. Appl. Environ. Microbiol. 68, 6036-6042.

[14] Schmidt AS, Bruun MS, Dalsgaard I, Pedersen K, Larsen JL (2000) Occurrence of antimicrobial resistance in fish-pathogenic and environmental bacteria associated with four Danish rainbow trout farms. Appl. Environ. Microbiol. 66, 4908-4915.

[15] Alcaide E, Blasco M-D, Esteve C (2005) Occurrence of drug-resistant bacteria in two European eel farms. Appl. Environ. Microbiol. 71, 3348-3350.

[16] Cabello FC (2006) Heavy use of prophylactic antibiotics in aquaculture: a growing problem for human and animal health and for the environment. Environ. Microbiol. 8, $1137-1144$.

[17] Huys G, Bartie K, Cnockaert M, Oanh DTH, Phuong NT, Somsiri T, Chinabut S, Yusoff FMd, Shariff M, Giacomini M, Teale A, Swings J (2007) Biodiversity of chloramphenicol-resistant mesophilic heterotrophs from Southeast Asian aquaculture environments. Res. Microbiol. 158, 228-235.

[18] Verschuere L, Rombaut G, Sorgeloos P, Verstraete W (2000) Probiotic bacteria as biological control agents in aquaculture. Microbiol. Mol. Biol. Rev. 64, 655-671.

[19] Gatesoupe FJ (1999) The use of probiotics in aquaculture. Aquaculture 180, 147-165.

[20] Gildberg A, Mikkelsen H (1998) Effects of supplementing the feed to Atlantic cod (Gadus morhua) fry with lactic acid bacteria and immuno-stimulating peptides during a challenge trial with Vibrio anguillarum. Aquaculture 167, 103-113. 
[21] Nikoskelainen S, Ouwehand AC, Bylund G, Salminen S (2001) Protection of rainbow trout (Oncorhynchus mykiss) from furunculosis by Lactobacillus rhamnosus. Aquaculture 198, 229-236.

[22] Kim DH, Austin B (2006) Innate immune responses in rainbow trout (Oncorhynchus mykiss, Walbaum) induced by probiotics. Fish Shellfish Immunol. 21, 513-524.

[23] Brunt J, Austin B (2005) Use of a probiotic to control lactococcosis and streptococcosis in rainbow trout, Oncorhynchus mykiss (Walbaum). J. Fish Dis. 28, 693-701.

[24] Brunt J, Newaj-Fyzul A, Austin B (2007) The development of probiotics for the control of multiple bacterial diseases of rainbow trout, Oncorhynchus mykiss (Walbaum). J. Fish Dis. $30,573-579$.

[25] Pieters N, Brunt J, Austin B, Lyndon AR (2008) Efficacy of in-feed probiotics against Aeromonas bestiarum and Ichthyophthirius multifiliis skin infections in rainbow trout (Oncorhynchus mykiss, Walbaum). J. Appl. Microbiol. 105, 723-732.

[26] Lee W, Oh JY, Ahn G, Kim EA, Kang N, Kim KN, Jeon YJ (2015) Effect of Ecklonia cava on the growth of lactic acid bacteria (LAB) and pathogen bacteria. In press

[27] Ahn G, Park E, Lee WW, Hyun JW, Lee KW, Shin TK, Jeon YJ, Park JW, Jee Y (2010) Enzymatic extract from Ecklonia cava induces the activation of lymphocytes by IL-2 production through the classical NF-кB pathway. Mar. Biotechnol (NY). 13, 66-73.

[28] Lee W, Ahn G, Lee BJ, Wijesinghe WA, Kim D, Yang H, Kim YM, Park SJ, Jee Y, Jeon YJ (2013) Radio-protective effect of polysaccharides isolated from Lactobacillus brevisfermented Ecklonia cava. Int. J. Biol. Macromol. 52, 260-266.

[29] Kumari J, Sahoo PK (2005) Effects of cyclophosphamide on the immune system and disease resistance of Asian catfish Clarias batrachus. Fish shellfish Immunol. 19, 307316.

[30] Amend DF (1981). Potency testing of fish vaccines. Dev. Biol. Standard. 49, 447-454. 
[31] Amar EC, Kiron V, Satoh S, Okamoto N, Watanabe T (2000) Effect of dietary bcarotene on the immune response of rainbow trout Oncorhynchus mykiss. Fish Sci. 66, 1068-1075.

[32] Ellis AE (1990) Lysozyme assays. In: Stolen JS, Fletcher TC, Anderson DP, Roberson BS, van Muiswinkel WD, editors. Techniques in fish immunology. Fair Haven, NJ: SOS Publications; 101-104.

[33] Yano T, Mangidaar REF, Matsuyama H (1989) Enhancement of the resistance of cap Cyprinus carpio, to experimental Edwardsiella tarda infection, by some $\beta$-1,3-glucans. Nippon Suisan Gakkaishi 55, 1815-1819.

[34] Joborn A, Olsson JC, Westerdahl A, Conway PL, Kjelleberg S (1997) Colonization in the fish intestinal tract and production of inhibitory substances in intestinal mucus and faecal extracts by Carnobacterium sp. strain K1. J. Fish Dis. 20, 383-392.

[35] Mie ttinen M, Vuopio-Varkila J, Varkila K (1996) Production of human tumor necrosis factor alpha, interleukin-6, and interleukin-10 is induced by lactic acid bacteria. Infect. Immun. 64, 5403-5405.

[36] Panigrahi A, Kiron V, Kobayashi T, Puangkaew J, Satoh S, Sugita H (2004) Immune responses in rainbow trout Oncorhynchus mykiss induced by a potential probiotic bacteria Lactobacillus rhamnosus JCM 1136. Vet. Immunol. Immunopathol. 102, 379-388.

[37] Cuesta A, Esteban MA, Meseguer J (2003) In vitro effect of chitin particles on innate cellular immune system of gilthead seabream (Sparus aurata L.). Fish Shellfish Immunol. $15,1-11$.

[38] Siwicki AK, Anderson DP, Rumsey GL (1004) Dietary intake of immunostimulants by rainbow trout affects non-specific immunity and protection against furunculosis. Vet. Immunol. Immunopathol.41, 125-139.

[39] Ellis AE (2001) Innate host defense mechanisms of fish against viruses and bacteria. 
Dev. Comp. Immunol. 25, 827-839.

[40] Raida MK, Larsen JL, Nielsen ME, Buchmann K (2003) Enhanced resistance of rainbow trout, Oncorhynchus mykiss (Walbaum), against Yersinia ruckeri challenge following oral administration of Bacillus subtilis and B. licheniformis (BioPlus2B). J. Fish Dis. 26, 495498.

[41] Vendrell D, Balcazar JL, de Blas I, Ruiz-Zarzuela I, Girones O, Muzquiz JL (2008) Protection of rainbow trout (Oncorhynchus mykiss) from lactococcosis by probiotic bacteria. Dev. Comp. Immunol. 31, 337-345.

[42] Fuller R, Probiotics in man and animals. J. Appl. Biotechnol. (1989) 66, 365-378.

[43] Magnadóttir B (2006) Innate immunity of fish (overview). Fish Shellfish Immunol. 20, $137-151$.

[44] Secombes CJ, Fletcher TC (1992) The role of phagocytes in the protective mechanisms of fish. Annu. Rev. Fish Dis. 2, 53-71.

[45] Cross ML (2002) Immunoregulation by probiotic lactobacilli: proTh1 signals and their relevance to human health. Clin. Appl. Immunol. Rev. 3, 115-125.

[46] Nakayamal T, Oishi K (2013) Influence of coffee (Coffea arabica) and galactooligosaccharide consumption on intestinal microbiota and the host responses. FEMS Microbiol. Lett. 343, 161-168.

[47] Ramnani P, Chitarrari R, Tuohy K, Grant J, Hotchkiss S, Philp K, Campbell R, Gill C, Rowland I (2012) In vitro fermentation and prebiotic potential of novel low molecular weight polysaccharides derived from agar and alginate seaweeds, Anaerobe 18, 1-6.

[48] Sweeney T, Dillon S, Fanning J, Egan J, O’Shea CJ, Figat S, Gutierrez JJM, Mannion C, Leonard F, O'Doherty JV (2011) Evaluation of seaweed-derived polysaccharides on indices of gastrointestinal fermentation and selected populations of microbiota in newly weaned pigs challenged with Salmonella Typhimurium, Anim. Feed Sci. Technol. 165, 
85-94.

[49] Matsuzaki T, Chin J (2000) Modulating immune responses with probiotic bacteria. Immunol. Cell. Biol. 78, 67-73.

[50] Secombes SJ (1990) Isolation of salmonid macrophages and analysis of their killing activity. In: Stolen JS, Fletcher TC, Anderson DP, Roberson BS, van Muiswinkel WD, editors. Techniques in fish immunology. Fair Haven, NJ: SOS Publications. 137-154.

[51] Jørgensen JB, Sharp GJE, Secombes CJ, Robertsen B (1993) Effect of yeast cell wall glucan on the bactericidal activity of rainbow trout macrophages. Fish Shellfish Immunol. $3,267-277$.

[52] Sharp GJE, Secombes CJ (1993) The role of reactive oxygen species in the killing of the bacterial fish pathogen Aeromonas salmonicida by rainbow trout macrophages. Fish Shellfish Immunol. 3, 119-129.

[53] Fletcher T, White A (1973) Lysozyme activity in the plaice (Pleuronectes platessa L.). Experientia 29, 1283-1285.

[54] Murray CK, Fletcher TC (1976) The immunohistochemical localization of lysozyme in plaice (Pleuronectes platessa L.) tissues. J. Fish Biol. 9, 329-334.

[55] Jolles P, Jolles J (1984) What's new in lysozyme research? Always a model system, today as yesterday. Mol. Cell. Biochem. 63, 165-189.

[56] Palic D, Andreasen C, Frank ED, Menzel BW, Roth J (2005a) Gradient separation and cytochemical characterisation of neutrophils from kidney of fathead minnow (Pimephales promelas Rafinesque, 1820). Fish Shellfish Immunol. 18, 263-267.

[57] Palic D, Andreasen C, Menzel BW, Roth J (2005b) A rapid, direct assay to measure degranulation of primary granules in neutrophils from kidney of fathead minnow (Pimephales promelas Rafinesque, 1820). Fish Shellfish Immunol. 19, 217-227. 
[58] Schiffrin EJ, Brassart D, Servin AL, Rochat F, Donnet-Hughes A (1997) Immune modulation of blood leukocytes in humans by lactic acid bacteria: criteria for strain selection. Am. J. Clin. Nutr.66, 515-520.

[59] Reilly P, O’Doherty JV, Pierce KM, Callan JJ, O’Sullivan JT, Sweeney T (2008) The effects of seaweed extract inclusion on gut morphology, selected intestinal microbiota, nutrient digestibility, volatile fatty acid concentrations and the immune status of the weaned pig. Animal 2, 1465-1473.

[60] Lynch MB, Sweeny T, Callan JJ, O’Sullivan JT, O’Doherty JV (2010) The effect of dietary laminaria derived laminarin and fucoidan on nutrient digestibility, nitrogen utilisation, intestinal mircoflora and volatile fatty acid concentration in pigs. J. Sci. Food. Agric. 90, 430-437.

[61] McDonnell P, Figat S, O' Doherty JV (2010) The effect of dietary laminarin and fucoidan in the diet of the weanling piglet on performance selected faecal microbial populations and volatile fatty acid concentrations. Animal 4, 579-585.

[62] O’Doherty JV, Dillon S, Figat S, Callan JJ, Sweeney T (2010) The effects of lactose inclusion and seaweed extract derived from Laminaria spp. on performance, digestibility of diet components and microbial populations in newly weaned pigs. Anim. Feed Sci. Technol. 157, 173-180. 


\section{Figure legends}

Fig. 1. Effects of $1.0 \% \mathrm{EC}, 0.1 \% \mathrm{EE}$, and $0.5 \% \mathrm{EE}$ on body weight, mortality, and accumulated mortality of olive flounder. Supplements containing $1.0 \% \mathrm{EC}, 0.1 \% \mathrm{EE}$, or $0.5 \%$ EE were added to the diet and $1.0 \%$ L. plantarum was added to all diets. The fish were fed twice a day for 16 weeks. The body weight (g/fish) (A) and mortality (C) of experimental olive flounder were recorded every 4 weeks for 16 weeks. The body weight (\%) (B) and the accumulated mortality (D) in experimental olive flounder were measured at 4 weeks. The accumulated mortality (E) was calculated as a percentage, with the control group being $100 \%$. Statistical evaluation was performed to compare the experimental and control groups. $p<$ 0.05 .

Fig. 2. Effects of $1.0 \% \mathrm{EC}, 0.1 \% \mathrm{EE}$, and $0.5 \% \mathrm{EE}$ on the respiratory burst activity of neutrophils, MPO activity, serum lysozyme activity, and growth rate of olive flounder. Supplements containing $1.0 \% \mathrm{EC}, 0.1 \% \mathrm{EE}$, or $0.5 \% \mathrm{EE}$ were added to the diet and $1.0 \% \mathrm{~L}$. plantarum was added to all diets. The fish were fed twice a day for 16 weeks. The respiratory burst activity of neutrophils (A), MPO activity (B), serum lysozyme activity (C) and growth rate (D) were measured at 16 weeks. Statistical evaluation was performed to compare the experimental and control groups. $p<0.05$.

Fig. 3. Effects of $1.0 \% \mathrm{EC}, 0.1 \% \mathrm{EE}$, and $0.5 \% \mathrm{EE}$ on the cumulative mortality of olive flounder infected by E. tarda (A), S. iniae (B), and V. harveyi (C). Supplements containing $1.0 \% \mathrm{EC}, 0.1 \% \mathrm{EE}$, or $0.5 \% \mathrm{EE}$ were added to the diet and $1.0 \%$ L. plantarum was added to all diets. The fish were fed twice a day for 2 weeks. Before feeding, all experimental fish were injected intraperitoneally with $100 \mu \mathrm{PBS}$ containing E. tarda, S. iniae, and V. harveyi at $3 \times 10^{5}$ ciliates $\mathrm{mL}^{-1}$. The accumulative mortality of infected olive flounder was recorded every day for 2 weeks. The accumulated mortality was calculated as a percentage, with day 0 
being $100 \%$. Statistical evaluation was performed to compare the experimental and control groups. $p<0.05$. 
Table 1. The composition of the experimental diets in all the groups.

\begin{tabular}{|c|c|c|c|c|c|c|c|c|c|}
\hline \multirow{2}{*}{$\begin{array}{l}\text { Experimenal } \\
\text { groups }\end{array}$} & \multicolumn{6}{|c|}{ Soft extruded pellets } & \multirow{2}{*}{$\begin{array}{l}\mathrm{EC} \\
(\%)\end{array}$} & \multirow{2}{*}{$\begin{array}{l}\mathbf{E E} \\
(\%)\end{array}$} & \multirow{2}{*}{$\begin{array}{l}\text { L. Plantarum } \\
\quad(\%)\end{array}$} \\
\hline & $\mathbf{C P}$ & $\mathbf{C F}$ & Ca & Ash & $\mathbf{F i}$ & $\mathbf{P}$ & & & \\
\hline Control group & 37 & 10 & 1.5 & 17.0 & 3.0 & 2.7 & - & - & 1.0 \\
\hline EC $1.0 \%$-fed group & 37 & 10 & 1.5 & 17.0 & 3.0 & 2.7 & 1.0 & - & 1.0 \\
\hline EE $0.1 \%$-fed group & 37 & 10 & 1.5 & 17.0 & 3.0 & 2.7 & - & 0.1 & 1.0 \\
\hline EE $0.5 \%$-fed group & 37 & 10 & 1.5 & 17.0 & 3.0 & 2.7 & - & 0.5 & 1.0 \\
\hline
\end{tabular}


Table 2. The oligonucleotide sequences of primers used in this study.

\begin{tabular}{ccccc}
\hline Primer & Oligonucleotide sequence (5'-3') & Expected sizes & Target gene & Reference \\
\hline VH-K1 & CAAGGCACACTTGACGAGCT & 638bp & rpoB & Oh $(2008)$ \\
VH-K2 & AAACCGCCTTCTTCAGTTAA & & & \\
etfD-F & GGTAACCTGATTTGGCGTTC & 445bp & etfD & $\begin{array}{c}\text { Castro et al. } \\
(2010)\end{array}$ \\
etfD-R & CCTAATTCTGTAATCGCTCC & & & Mata et al. \\
LOX-1 & AAGGGGAAATCGCAAGTGCC & & lcto & $(2004)$ \\
LOX-2 & ATATCTGATTGGGCCGTCTAA & & & \\
\hline
\end{tabular}


Table 3. Effects of $1.0 \% \mathrm{EC}, 0.1 \% \mathrm{EE}$ and $0.5 \% \mathrm{EE}$ on the serum biochemical profiles of olive flounder.

0 wk

\begin{tabular}{|c|c|c|c|c|c|c|}
\hline$\underset{(\mathbf{g} / \mathbf{d L})}{\mathbf{T P}^{\mathrm{a}}}$ & $\begin{array}{c}\text { TRIG }^{b} \\
(\mathrm{mg} / \mathrm{dL})\end{array}$ & $\begin{array}{l}\mathbf{A S T}^{\mathbf{c}} \\
(\mathrm{U} / \mathrm{L})\end{array}$ & $\begin{array}{l}\mathbf{A L T}^{\mathbf{d}} \\
(\mathbf{U} / \mathbf{L})\end{array}$ & $\begin{array}{c}\text { GLU }^{\mathrm{e}} \\
(\mathrm{mg} / \mathrm{dL})\end{array}$ & $\begin{array}{c}\text { PHOS }^{\mathbf{f}} \\
(\mathrm{mg} / \mathrm{dL})\end{array}$ & $\begin{array}{l}\mathrm{CHOL}^{\mathrm{g}} \\
(\mathrm{mg} / \mathrm{dL})\end{array}$ \\
\hline
\end{tabular}

Control $\quad 5.2 \pm 1.4 \quad 70.0 \pm 6.2 \quad 73.5 \pm 14.8 \quad<10 \quad 21.5 \pm 8.0 \quad 11.1 \pm 6.6179 .5 \pm 11.222 .2 \pm 2.2$

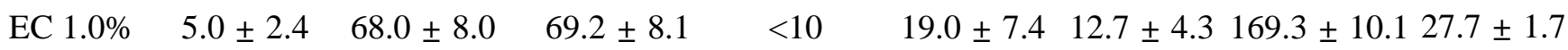

EE $0.1 \% \quad 4.7 \pm 6.3 \quad 66.0 \pm 9.6 \quad 72.1 \pm 10.0 \quad<10 \quad 19.0 \pm 12.410 .5 \pm 6.4156 .6 \pm 12.717 .0 \pm 6.5$

EE $0.5 \% \quad 4.5 \pm 3.1 \quad 66.0 \pm 6.7 \quad 64.6 \pm 7.6 \quad<10 \quad 26.0 \pm 10.810 .6 \pm 7.0180 .4 \pm 24.715 .4 \pm 3.8$

Control $\quad 5.2 \pm 0.3 \quad 111.7 \pm 31.8 \quad 59.8 \pm 15.0 \quad 16.3 \pm 5.9 \quad 22.3 \pm 3.6 \quad 9.7 \pm 0.7 \quad 175.2 \pm 34.418 .0 \pm 2.4$

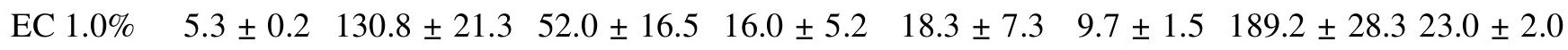
16 wks

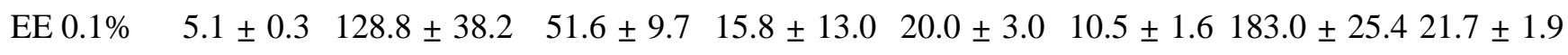

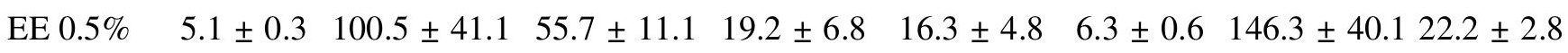

${ }^{\mathrm{a} T P}$ : Total protein, ${ }^{\mathrm{b} T R I G: ~ T r y g l y c e r i d e, ~}{ }^{\mathrm{c} A S T}$ : Aspartate aminotransferase, ${ }^{\mathrm{d} A L T}$ : Alanine aminotransferase, ${ }^{\mathrm{e}} \mathrm{GLU}$ : Glucose, ${ }^{\mathrm{f}} \mathrm{PHOS}$ : Phosphorus, ${ }^{\mathrm{g}} \mathrm{CHOL}$ : Cholesterol, hHT: Hematocrit 


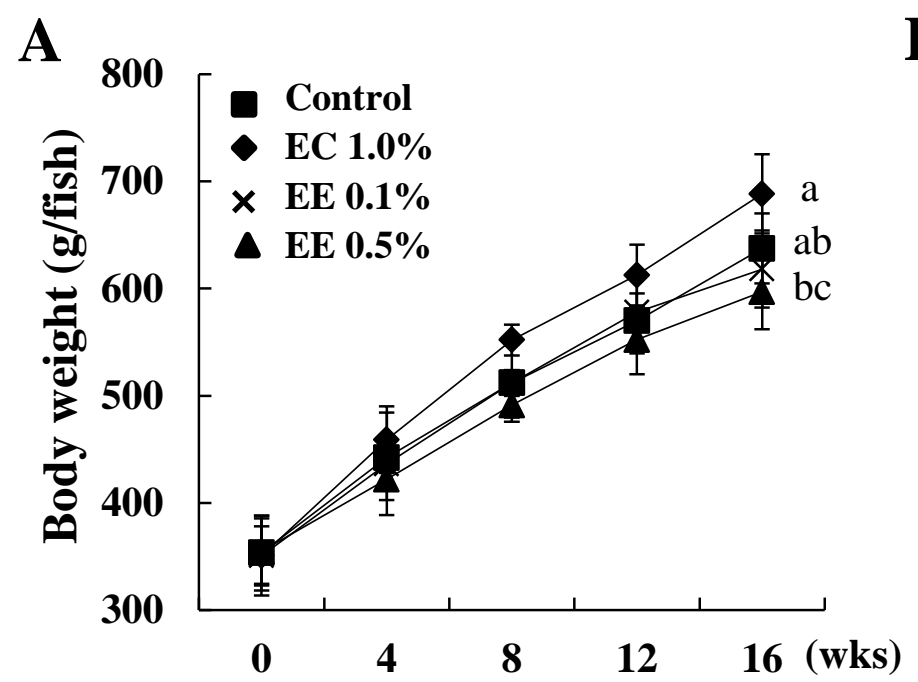

C

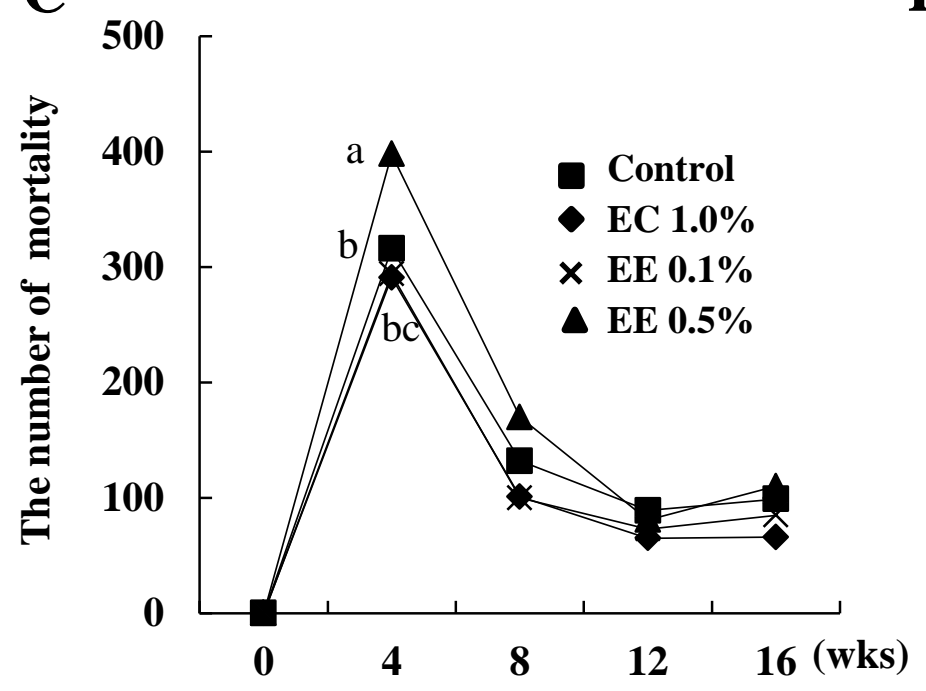

E

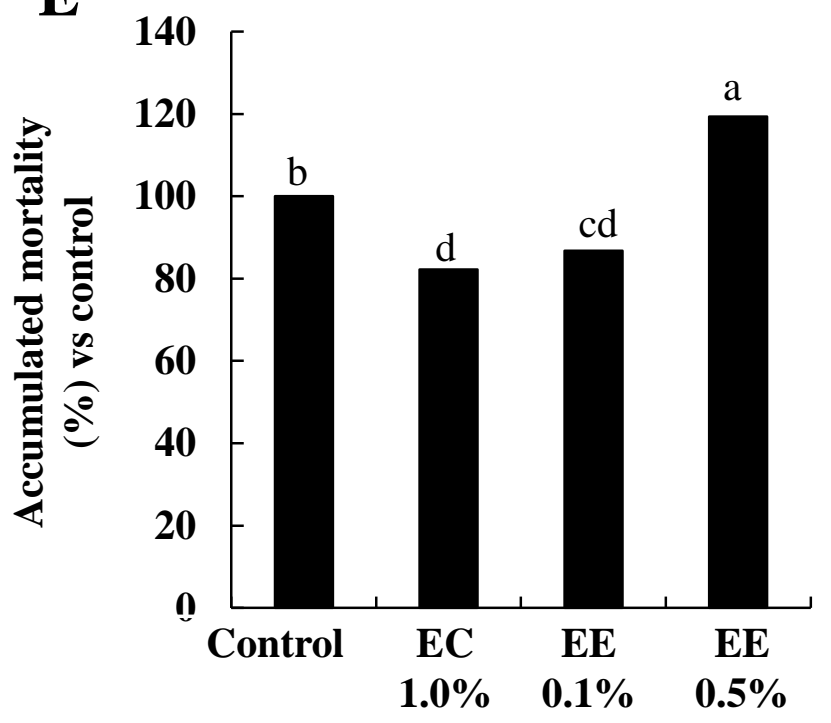

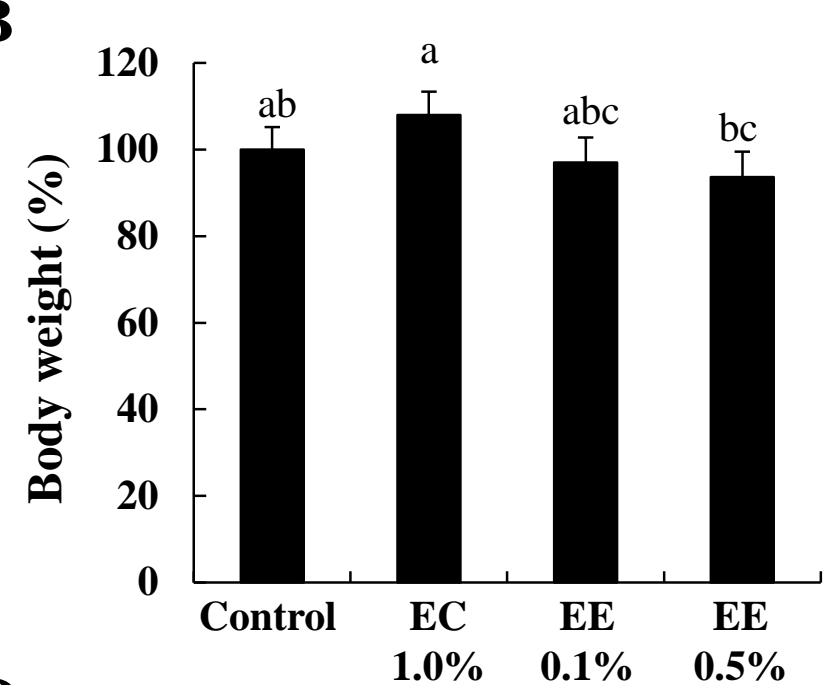

D

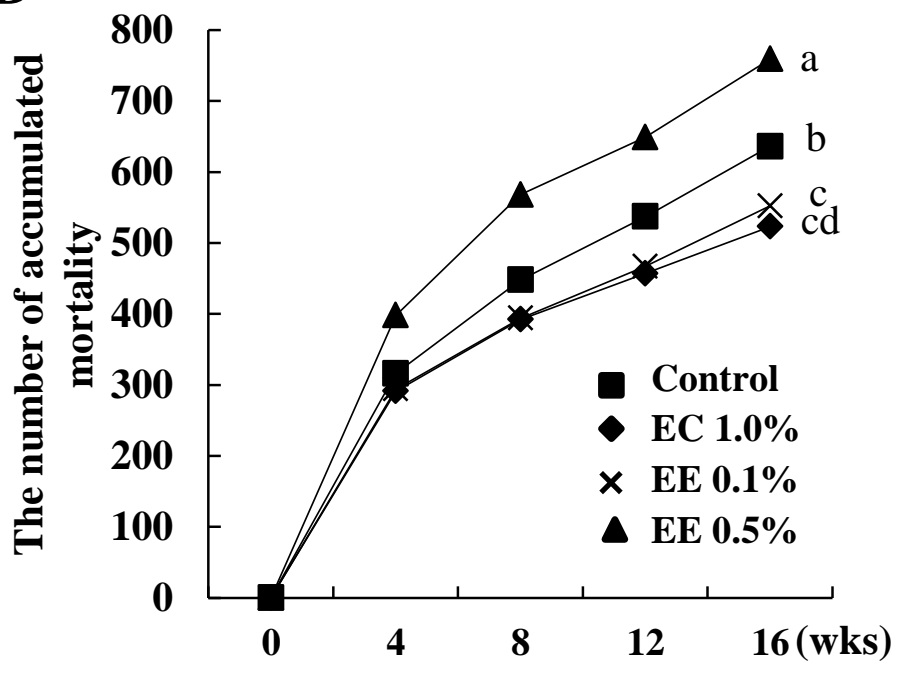

Figure 1. Lee et al. 
A

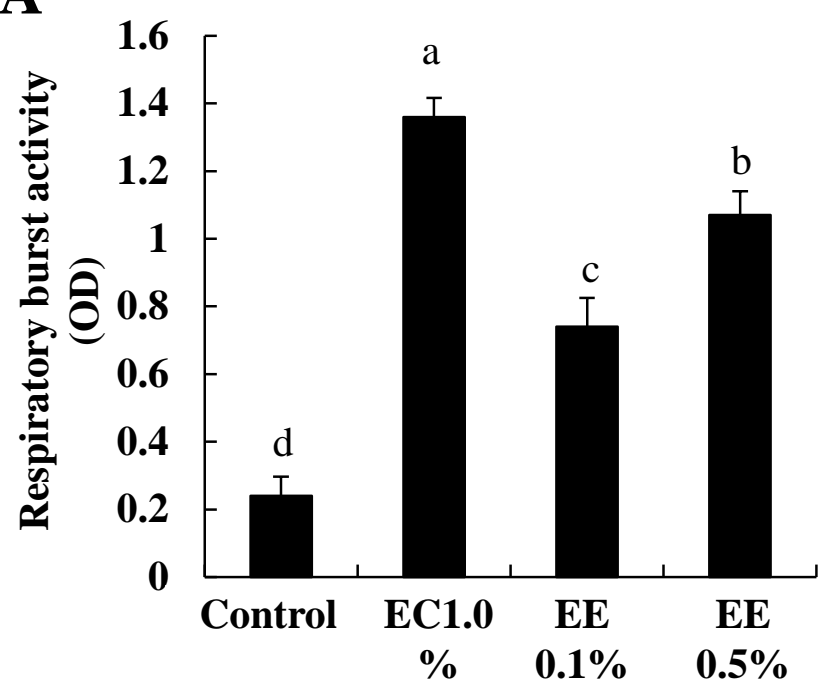

B

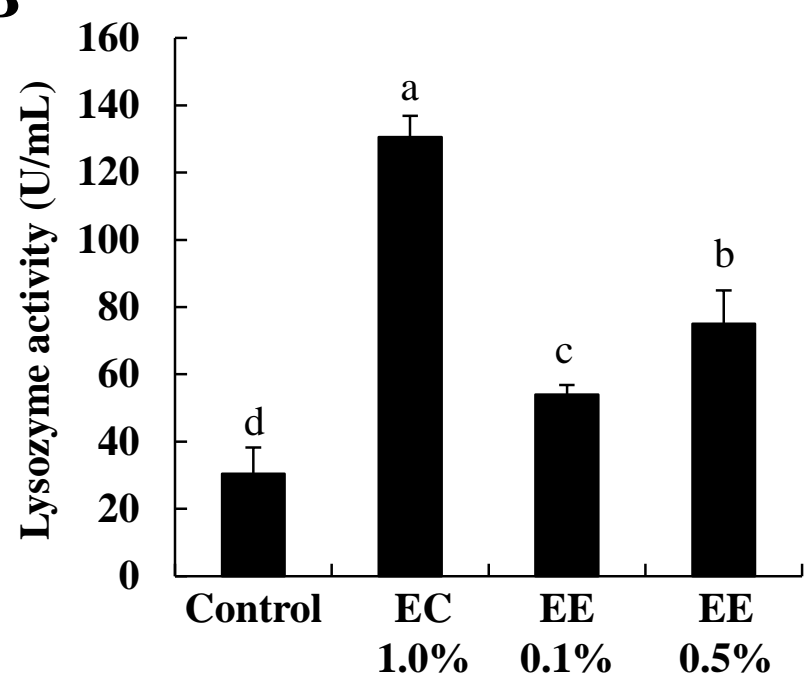

C

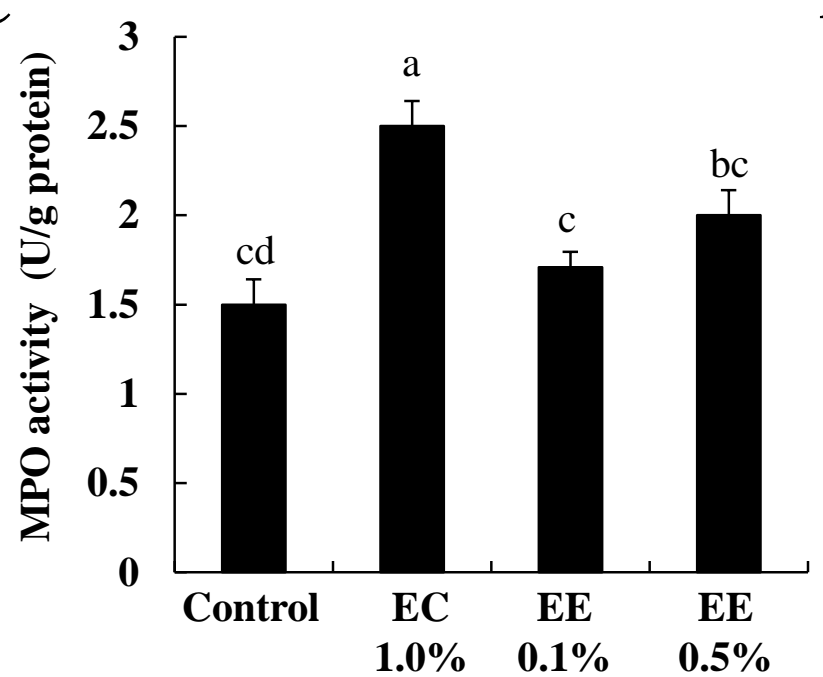

D

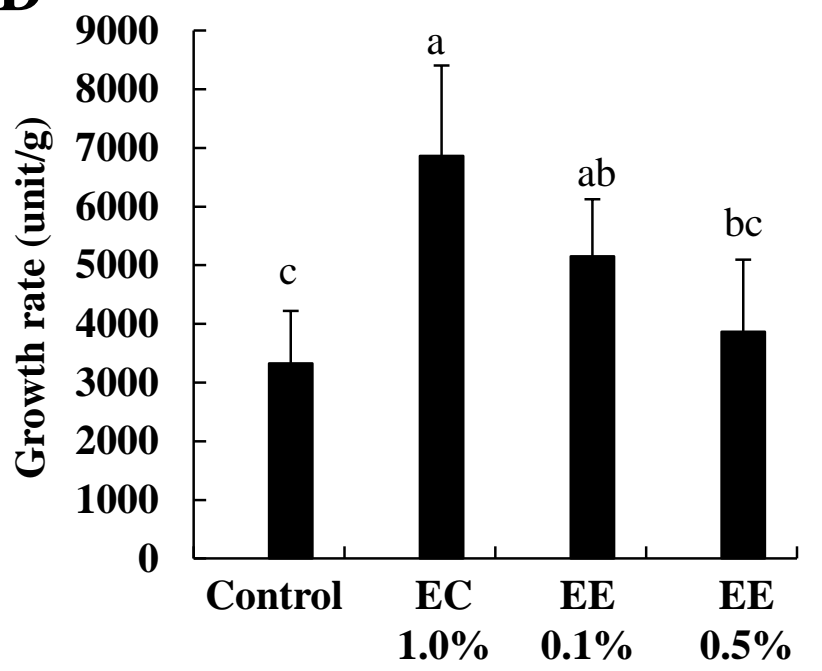

Figure 2. Lee et al. 
A
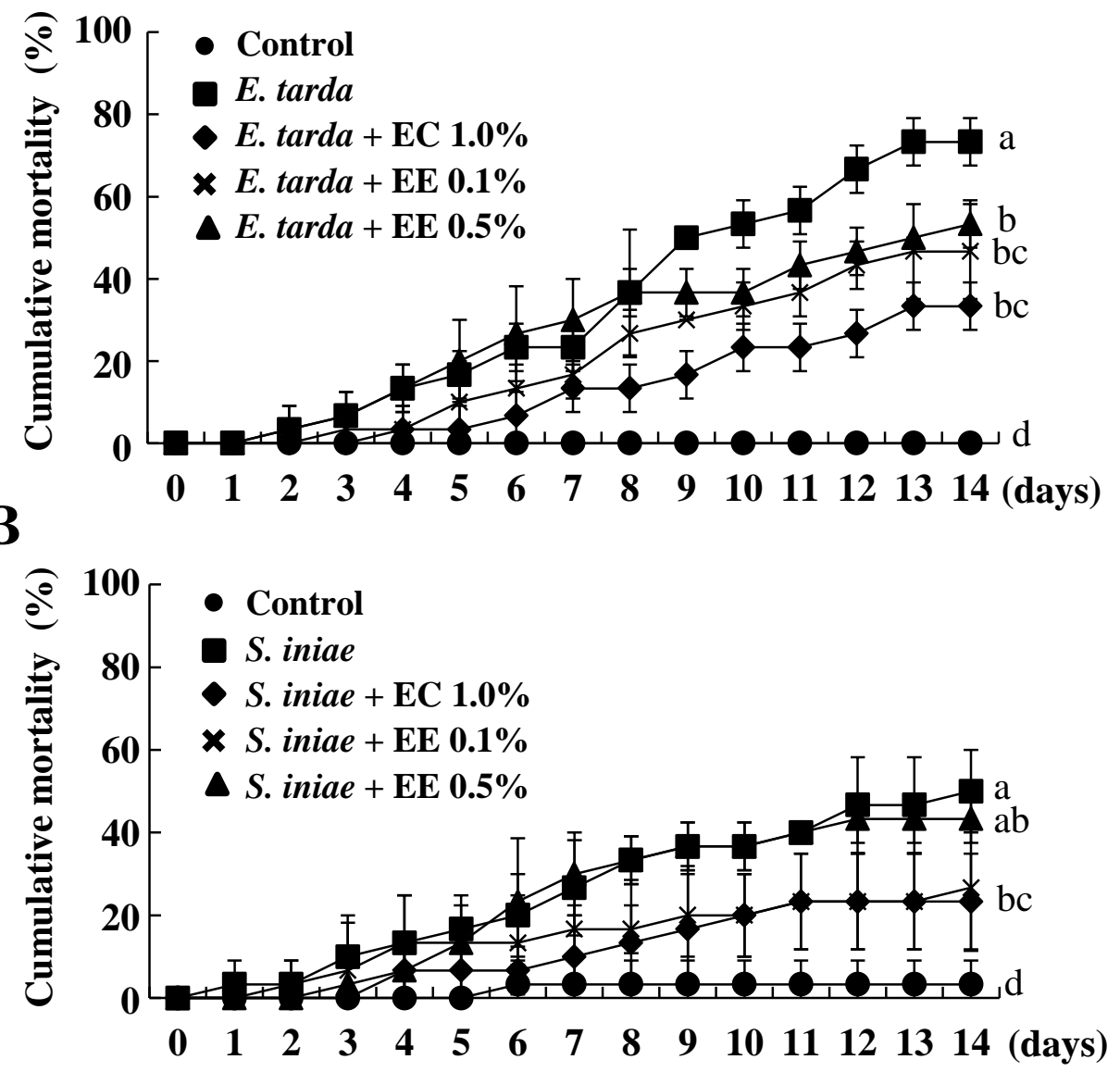

C

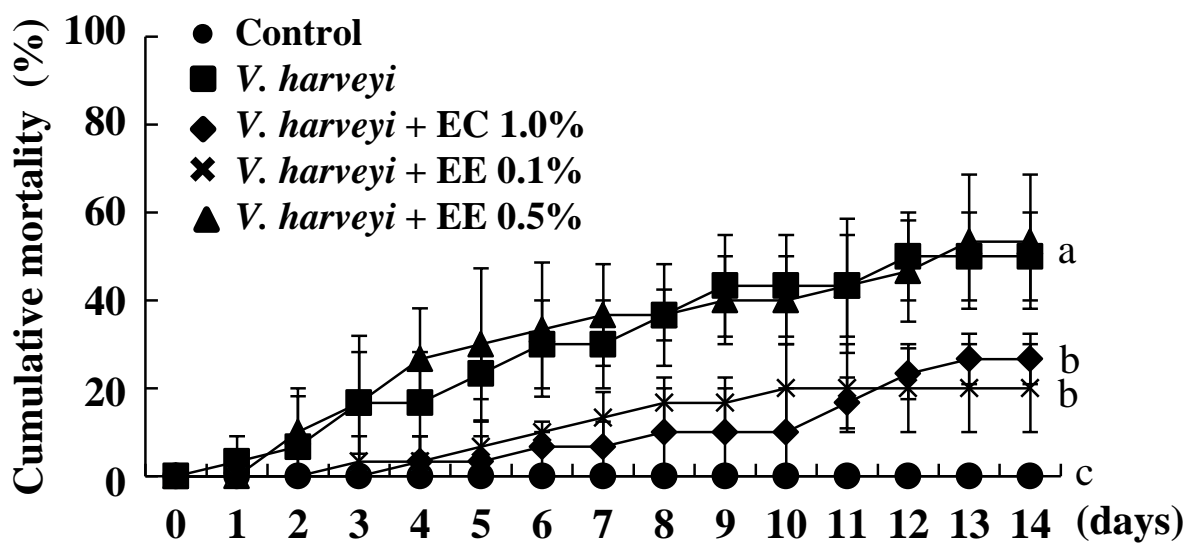

Figure 3. Lee et al. 